Ophthalmoscope: The media are clear except in extreme upper temporal periphery, where there are several large vitreous haemorrhages which partially obscure an extensive concentric rupture of the choroid in this region. No part of the optic disc is visible : it is completely hidden by a lobulated mass, irregular in outline, semi-translucent and gelatinous in appearance, bluish white in colour. The mass consists of innumerable but discrete round hyaline bodies lying in front of the disc and retinal vessels; the latter are for the main part buried in the mass, emerging near its edge, and are, with two exceptions, healthy in appearance. Near the upper edge there are two small and very tortuous dilated veins coursing over the upper quarter of its surface. Two small arterial branches running from beneath the mass towards the macula present the signs of perivasculitis. There are no newly formed vessels present, and no other signs of any previous inflammatory changes in the eye. The highest plus lens which focusses the surface of the mass is $3 \mathrm{D}$.

I am indebted to Sergt. Maxwell, R.A.M.C., for the excellent painting of the fundus seen by the direct method.

\title{
A REVERSIBLE SCREEN STEREOSCOPE *
}

\section{A. C. Hudson, LONDON.}

THIS instrument is a modification of one first described several years ago (Ophthal. Rev., December, 1912), and exhibited at the meeting of the Ophthalmological Society of the United Kingdon in 1914.

The eye pieces consist of plane-prisms (in place of the original sphero-prisms), each of which is of $4^{\circ}$ angle of deviation, and is mounted at the extremity of a bar bearing at its other extremity a cell to hold a diagram or picture. The bars cross one another obliquely, the degree of obliquity of the angle of crossing being determined at any moment by the position of a vertical pin which can be moved freely in an antero-posterior direction within a slot which traverses each bar longitudinally. This pin supports the screen, which, by means of a hinge mechanism, can be converted from a central narrow screen to two screens with a central aperture, and vice versâ. When the screen is disposed in the first-mentioned position, and the prisms are arranged base outwards (Fig. 1), the picture in the right-hand cell is visible to, and that in the left-hand cell screened from, the right eye, while the left eye can see only the

\footnotetext{
* Shown at the meeting of the Ophthalmological Society U.K., April, 1918.
} 
picture in the left-hand cell : fusion of the images of the two pictures, as they are separated by approximation of the screen to the eyes, involves divergence of the visual axes. With the screen disposed in the form of two lateral wings, and the prisms placed

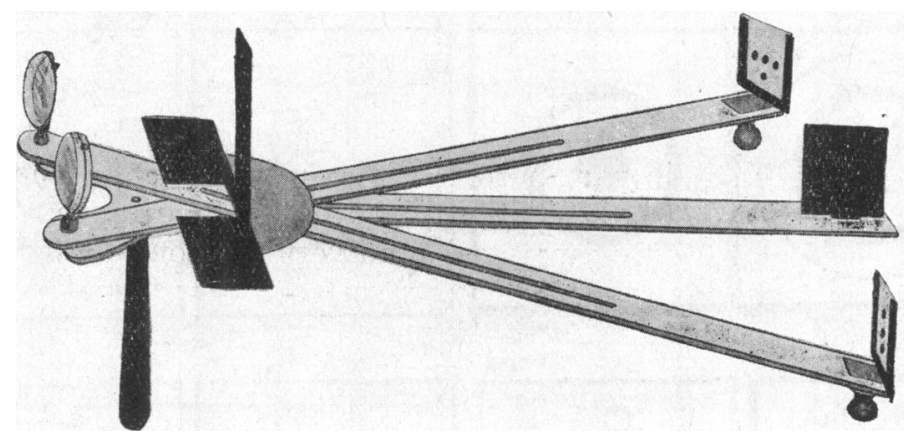

FIG. 1.

base inwards (Fig. 2), the right eye can see only the left-hand, and the left eye only the right-hand, picture ; fusion of the two pictures, as they are separated by approximation of the screen to the eyes, involves convergence of the visual axes. It is obvious that we thus possess a means of utilizing the desire to maintain fusion of the

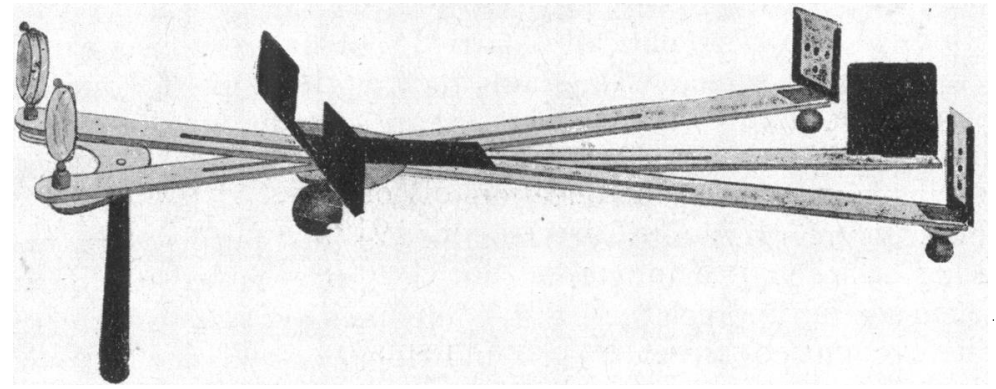

FIG. 2.

images of the two pictures, where such exists, for the purpose of producing either divergence or convergence of the visual axes, or of reducing an existing lack of parallelism.

The instrument is, in the first place, suitable for examination as to the existence and degree of binocular and stereoscopic vision, the elicitation of binocular vision being assisted, if necessary, by a use of the vertical screen between the pictures, in such a manner as to emphasize the illumination of the picture seen by the visually more defective eye, as recommended by Worth. For this examination the diagrams in Figs. 3 and 4 may be used.

In the examination and treatment of squint the arrangement of the prisms and screen should at first be such as corresponds with 
the abnormality of the visual axis. When fusion of the two pictures has been obtained, if necessary with the help of the vertical screen, the desire to maintain it in spite of the alteration in the direction of the visual axes necessitated by antero-posterior movement of the screen enables exercise of the extra-ocular muscles in the appropriate

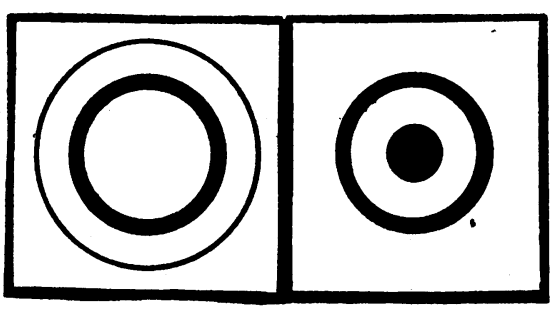

FIG. 3 .

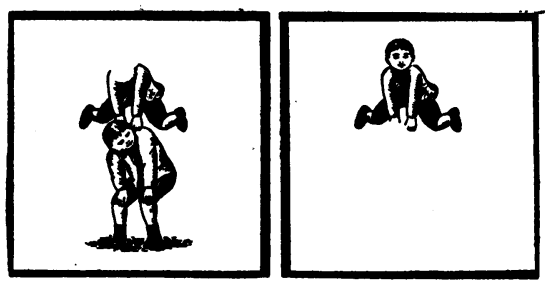

FIG. 5 .

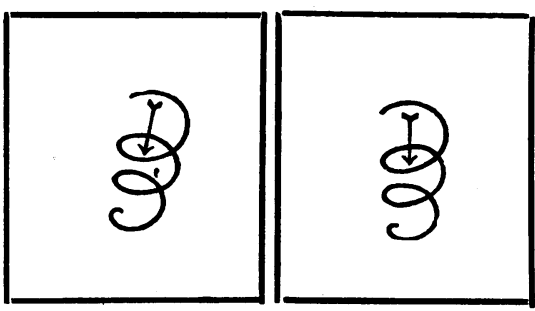

FIG. 4.

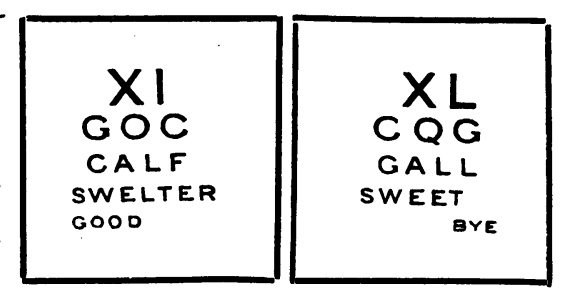

FIG. 6.

direction to be systematically carried out in response to such movement of the screen. Diagrams such as those in Fig. 3 and the various fusion pictures, such as Fig. 5, are suitable for this purpose.

Similar exercises may be practised with advantage in cases of lateral heterophoria and defective convergence.

The instrument is also very suitable for test purposes in many cases of suspected malingering, in view of the great 'difficulty experienced in appreciating the component portion of a fused picture recognized by each eye individually, and the ease with which any attempt to overcome this difficulty by momentary closure of one eye can be detected and circumvented by the examiner. The difficulties in the way of sustaining a false claim to defective vision may be further increased by the use of the vertical screen between the pictures in conjunction with an artificial light, in such a manner that the picture seen by the alleged defective eye is strongly illuminated, while that facing the better eye is more or less completely obscured. In a series of examinations the arrangement of the prisms and screen may be varied with advantage. The diagrams in Fig. 6, which should be constructed on the Snellen scale, afford an example of one of the many tests applicable in cases of this kind. 